\title{
DEVELOPING CONNECTED SPEECH BY STUDENTS WITH INTELLECTUAL DEFICIENCY IN INTERDISCIPLINE CONNECTION
}

\section{D.G. Azizova}

\author{
Senior Lecturer, Tashkent State Pedagogical University Tashkent, Uzbekistan
}

\section{ABSTRACT}

In the article, a lot of attention has always been paid to the problem of formation of speech activity of students with intellektual deficiencies.Possible ways to formulate the language component of the pupils,information on the formation of connected speech are presented.

KEYWORDS:- Intellekt students with a visual deficiency, the surrounding world, connected speech,language,monological speech,dialogical speech ,boosted speech,psychological characteristics,the process of Communication, Speech Development.

\section{INTRODUCTION}

One of the key components in the correctional education of students with intellectual disabilities is the development of connected speech. Many scholars (linguists, philosophers, psychologists, sociologists, teachers) are concerned about the decline in the overall level of speech culture. Therefore, systematic work on the formation of language competence is a requirement of the times.

In this regard, the task of a modern specialized special school is to achieve the most effective social form of organizing children's educational activities.

Much attention has always been paid to the problem of shaping the speech activity of students with intellectual disabilities. At present, general requirements for speech development of special school students have been established.
One of the urgent tasks of today is to identify possible ways to form the language competence of students of specialized special schools, to analyze monologue and dialogic forms of speech, to determine the psychological features of the formation of oral and written speech of schoolchildren. Consequently, monologue speech is the most complex, random, most organized type of speech and therefore requires special speech training. In this regard, one of the problems that meets current and modern requirements is the study of related speech, the search for appropriate methods and techniques, forms and means of developing speech activity in children.

\section{THE MAIN RESULTS AND FINDINGS}

Children with intellectual disabilities learn their mother tongue through speech activities, speech perception and speech. At the same time, 
CURRENT RESEARCH JOURNAL OF PEDAGOGICS 2(11): 115-121,

November 2021 DOI: https://doi.org/10.37547/pedagogics-crjp-02-11-21

ISSN 2767-3278

(C)2021 Master Journals

Crossref do: 81 Google

Accepted 25th November, 2021 \& Published 30 ${ }^{\text {th }}$ November, 2021

speaking activities are shaped by other disciplines, such as reading, the environment, and speech development. That is why it is very important to create conditions for wellconnected speech activity, communication, expression of ideas of children with intellectual disabilities. This explains the relevance of the topic, so it was the basis for choosing our research topic, problem, object, and subject matter.

Problems of speech activity have attracted the attention of many scholars. In particular, Russian scholars L. A. Wenger, B. F., V. V. L. S. Lomov Bogoslovsky Vygotsky, V. A. Krutetsky, A. N., A. R., S. L. Leontiev Luria Rubinstein, et al.

Leading scientists of the Republic L.R.Muminova, R.Shomakhmudova, M.Yu.Ayupova, P.M.Pulatova, H.M.Pulatova, D.A.Nurkeldieva, M.P.Khamidova, N.S.Musaeva and others .

It allows to create scientifically based conditions for determining the conditions of individualization of activities in the development of speech activity in children. Consequently, monologue speech is the most complex, random, most organized type of speech and therefore requires the cultivation of a special speech culture.

However, practice shows that despite the increased interest in the problem, the level of speech development of primary school students of a specialized special school, i.e., the solution of problems related to connected speech development, is insufficiently developed. In this regard, modern and methodologically organized correctional pedagogies play an important role in the development of speech. One way to do this is to work on developing connected speech in the lessons of the world around us.

The limited perception of the environment before the inclusion of education in mentally retarded children with intellectual disabilities, the teaching of this subject also involves the formation of students' verbal logic thinking and speech at the same time.

In special pedagogy, methodological developments in the development of connected speech in environmental lessons are insufficient, which requires the improvement of connected speech development in students with intellectual disabilities. It is important in the process of studying the environment as a factor of ecological, moral, aesthetic, social and verbal development, as well as the correctional upbringing of children.

In order to acquaint students with intellectual disabilities with a specific environment, the teacher is required to build the learning process in accordance with the age and individual characteristics of students, to choose a certain type of material, conscious perception, to select methodologically acceptable for perfect mastering.

Based on the above, we can determine the urgency of this problem. The relevance of this study is determined by the fact that the study of mechanisms of consistent speech development is an important task of the education system.

How to organize work on the formation of connected speech skills, to teach students with intellectual disabilities to express themselves fully, competently and clearly, what are the directions and stages of work on the development of connected speech, what types of work are most effective? These questions served as the basis for choosing the topic of the work presented.

The object of research is the coherent speech of children with intellectual disabilities.

The research topic is the process of developing coherent speech in children with intellectual disabilities.

The main goal of the work is to identify 
CURRENT RESEARCH JOURNAL OF PEDAGOGICS 2(11): 115-121,

November 2021 DOI: https://doi.org/10.37547/pedagogics-crjp-02-11-21

ISSN 2767-3278

(C)2021 Master Journals

Crossref do) 81 Google

Accepted 25th November, 2021 \& Published 30 ${ }^{\text {th }}$ November, 2021

opportunities for the development of coherent speech of a primary school student with intellectual disabilities in the lessons of the world around us.

The objectives of the study are as follows:

1. To study the theoretical aspects of developing connected speech in primary school students with intellectual disabilities.

2. Develop and test a program for the development of coherent oral speech in environmental lessons.

3. To determine the level of development of connected speech in students with intellectual disabilities before and after testing the program.

4. Selection of methodological methods for the development of connected speech in primary school students with intellectual disabilities.

Research methods: analysis of the relevant literature, survey, analysis of the results obtained during the study.

Consistent speech is understood as "a semantically extended statement (a series of logical conjunctions) that provides communication and mutual understanding." Coherence, p. L. Rubinstein believes that "for the listener or reader, from the point of view of his intellect, the speaker or writer's opinion is sufficient for speech design." Therefore, the main characteristic of a connected speech is that it is understandable to the interlocutor.

A coherent speech is a speech that reflects all the important aspects of its topic content. Speech can be incoherent for two reasons: either because these connections are not made and not expressed in the speaker's opinion, or because these connections are not properly identified in his speech.

In the methodology, the term "connected speech" is used in several senses: 1) process, activity of the speaker; 2) the product, result, text, statement of this activity. The terms "speaking" and "text" are used synonymously. According to T. A. Ladyzhenskaya, "both speech activity and the result of this activity: a particular speech work, including more. Its core meaning".

The main function of connected speech is communicative. 2 main configurations - dialogue and monologue. Each of these configurations contains specific features that determine the nature of the methodology for forming them.

In the linguistic and psychological literature, dialogic and monologic speech are considered in terms of their opposition. They differ in their communicative orientation, linguistic and psychological characteristics.

Dialogic speech implies a particularly colorful expression of the communicative function of language. Experts call dialogue the basic natural configuration of language communication, the traditional configuration of speech communication. The main characteristic feature of the dialogue is that the 1st interlocutor listens to the second sentence and then exchanges it with the speaker. Also, in a conversation, the interlocutors always understand what is being discussed and there is no need to post opinions and statements. Oral dialogic speech takes place in a specific situation and is accompanied by gestures, facial expressions, intonation. Hence the language design of the dialogue. The speech in it may be incomplete, abbreviated, and in some cases fragmented. The dialogue is characterized by: spoken word and phraseology; conceptual, intelligible, abrupt; elementary and complex compound sentences; short-term foresight. Communication is maintained by 2 interlocutors. Dialogic speech is characterized by voluntariness, reactivity. It is characterized by dialogue standards and stereotypes, speech stereotypes, stable communication formulas, common, frequently used and used. 
CURRENT RESEARCH JOURNAL OF PEDAGOGICS 2(11): 115-121,

November 2021 DOI: https://doi.org/10.37547/pedagogics-crjp-02-11-21

ISSN 2767-3278

(C)2021 Master Journals

Crossref do: 81 Google

Accepted 25th November, 2021 \& Published 30 ${ }^{\text {th }}$ November, 2021

A monologue is a coherent, logically coherent statement that flows for a relatively long time, not intended for immediate response from the speech-listener. It has an incomparably more complex structure and represents a 1st person opinion that is unknown to the audience. Therefore, the statement contains the most complete formulation of the data, it is detailed. In a monologue, the internal organization, the longest predicted idea, and most importantly the concept of the idea are needed. Non-verbal means (gestures, facial expressions, intonation), where sensual, active, clear speaking skills are also important, but they are subordinate. The monologue is characterized by: literary vocabulary; expression completeness, completeness, logical completeness; syntactic formalism (detailed system of connecting components); the monologue sequence is supported by a speaker.

These 2 forms of speech are also distinguished by motives. Monologue speech is motivated by internal motives, the essence of which and the means of language are chosen directly by the speaker. Dialogic speech is stimulated not only by internal but also by external motives (the situation in which the dialogue takes place, the statements of the interlocutor).

Consequently, for children with intellectual disabilities, monologue speech is the most complex, random, most organized type of speech and therefore requires special speech training.

Despite the important differences, dialogue and monologue are intertwined. In the process of communication, monologue speech is organically linked to dialogic speech, and monologue can have dialogic features. Often the interaction is done in the form of a dialogue with monologue suffixes, along with short words, the most detailed statements are used, consisting of several sentences and various information (message, appendix or explanation of what is stated). One of the 1st researchers of communication in Russian scholars is L.S. P. Yakubinsky and AV Yastrebova noted that the extreme cases of dialogue and monologue are connected with each other through a number of intermediate forms. One of them is the slowest rate of replication exchange from a normal conversation, their large size and consultation, a conversation that differs from the arbitrary nature of speech. Such a conversation is called a spontaneous (unprepared) conversation, as opposed to a prepared dialogue. In the pedagogical literature, the special place of consistent monologue speech is often emphasized. At the same time, it is equally important to take a dialogical form of communication, because in a broad sense, "dialogic communication is an almost universal phenomenon that conducts all human speech and all relations and appearances of human life without exception."

The formation of both forms of compound speech plays a major role in a child's speech development. The study of connected speech can be seen as both a goal and a means of mastering practical language. Mastering different aspects of speech is an important condition for the formation of connected speech, while the formation of connected speech facilitates the independent use of individual words and syntactic constructions by the child. Consistent speech masters all the achievements of children, without exception, in mastering the style close to each other, its sound regime, lexicographic structure, grammatical structure.

Psychologists emphasize that the close relationship between a child's speech and mental development is clearly manifested in consistent speech. The child learns to think by learning to speak, but he also improves speech by learning to think.

Consistent speech performs basic social 
CURRENT RESEARCH JOURNAL OF PEDAGOGICS 2(11): 115-121,

November 2021 DOI: https://doi.org/10.37547/pedagogics-crjp-02-11-21

ISSN 2767-3278

(C)2021 Master Journals

Crossref do: 81 Google

Accepted 25th November, 2021 \& Published 30 ${ }^{\text {th }}$ November, 2021

functions: it can help the child to establish relationships with others, to establish and regulate norms of behavior in society, which is an important condition for the formation of his personality.

Teaching related speech also has an impact on aesthetic education: retelling of literary works, independent children's compositions shape the brightness and expressiveness of speech, enrich the child's artistic and speech experience.

Consistency is a more complex form of speech activity. It is distinguished only by its own special features. Consistent speech has the character of a regular alternative presentation. A coherent message implies a detailed statement. Thus, coherent speech is understood as a detailed statement of a specific content. Which is done logically, alternately, is grammatically correct.

In the work of many authors, the formation of coherent speech in mentally retarded children is carried out slowly and is characterized by certain qualitative features (A.N. Gvozdev, L. N. Efimenkova, V. G. Petrova, etc.). Mentally retarded students are much later in the questionand-answer phase of speech, the situational speech phase. Even in the context of speech therapy, the transition to independent speech is very difficult for these children and is often delayed until the senior classes of the auxiliary school. In the process of connected speech, mentally retarded primary school students need constant encouragement from the teacher, regular help, which manifests itself in the form of questions or advice.

Disorders of consistent oral speech development result from a whole set of causes. In addition to cognitive impairment, it plays an important role in the development of coherent speech. Dialogic speech is known to precede monologue speech and prepare for its formation. Mentally retarded children often do not understand the need to convey clearly and clearly the essence of an action in order to be clear to the interlocutor.

Another reason is that the speech activity of this group of children is very short and quickly incomprehensible. There is no external stimulus in the process of monologue speech, the detailing and formulation of the story is done personally by the child. The emptiness of the volitional field of mentally retarded children plays a key role in disrupting the flow of speech. In such cases, as the child becomes interested in the topic of the statement, the type of coherent statements will also change, they will be the most detailed and consistent, and the number of words in the sentence will gradually increase. Thus, motivation also affects the nature of coherent speech.

The specific features of coherent statements are largely determined by the nature of the tasks (presentation, narration according to a series of plot illustrations, independent story according to the presentation, etc.). Studies by L. V. Zankov have shown that the number of words in stories in mentally retarded children is 2.5 times greater than in stories on a given topic, according to a series of plot illustrations. The authors explain this by the fact that a series of plot illustrations determines the sequence of events, their dynamics..

Much easier than an independent story, retelling is done in mentally retarded children. Retelling does not imply the formation of an independent conspiracy in any way. Detailed definition of the assigned topic, setting the order of events. Mastering the content of the text plays an important role in retelling. But the retaliation of mentally retarded students also has its own characteristics. Children often add missing events, details to a story. These additions are explained by erratic associations, inaccuracies in ideas and knowledge.

\section{Conclusion}


CURRENT RESEARCH JOURNAL OF PEDAGOGICS 2(11): 115-121,

November 2021 DOI: https://doi.org/10.37547/pedagogics-crjp-02-11-21

ISSN 2767-3278

(C)2021 Master Journals

Crossref do: 81 Google

Accepted 25th November, 2021 \& Published 30 ${ }^{\text {th }}$ November, 2021

Based on the above, it can be concluded that mentally retarded children violated both the content plan and the coherent text writing plan. However, the violation of the content plan, the internal (semantic) program of consistent speech, is particularly general and enduring, which confirms the need for significant work on the development of consistent speech.

The mentally retarded have poor lexicographical resources, incorrect use of words, vocabulary update problems are more important than usual, passive vocabulary has an advantage over assets, unformed structure of word meaning, disruption of the process of organizing semantic fields.

It is observed that the grammatical aspect of speech expressed in agrammatism is not formed in the difficulties of mentally retarded students in performing many tasks that require grammatical generalizations. Morphological forms of perception and word formation, syntactic structures of speech are not sufficiently formed.

Mentally retarded children have very poor and vague morphological generalizations, ideas about the morphological structure of a word and the syntactic relationship of words in a sentence, and an insufficiently formed system of grammatical meanings. The lack of lexicogrammatic structure of speech is especially noticeable in coherent speech.

Communication is one of the forms of human interaction. A person's entire life is spent interacting with other people. Speech is one of the most important and unchanging components of human communication. Consistent speech development is noted in absolutely all children with intellectual disabilities, and this has a negative impact on the formation, upbringing, and socialization of the child. Appropriate and targeted activities for the formation of connected speech help to form mental activity, master the school curriculum, improve the interaction and social adaptation of students of specialized schools.

\section{REFERENCES}

1. Mirziyoev Sh.M. Critical analysis, strict discipline and personal responsibility should be the daily rule of every leader's work. -T .: "Uzbekistan". - 2017.- 102 p.

2. Aleseeva M.M. Methods of teaching the Russian language in a special (correctional) school [Text]: textbook. for stud. defectol. fac. pedagogical universities / A.K. Aksyonova. - M.: Humanities. ed. center "VLADOS", 2004. - 316 p.

3. Yakubinsky, LP On dialogical speech [Text] // Russian speech / ed. L. V. Shcherba. - M . Pedagogika, 1976 .- 195 p.

4. Yastrebova, A. V. Overcoming OHR in children [Text] / Yastrebova A. V. MAFKTI, 1999.

5. Gvozdev, A. N. Questions of studying children's speech [Text] / Gvozdev A. N. M .: Pedagogy, 1961. - 170 p.

6. Zankov, L. V. Some questions of personality development of mentally retarded schoolchildren at the first stages of education [Text] / L. V. Zankov. - M .: Publishing house "APN RSFSR". - 307 p.

7. Zankov, L. V. Questions of psychology of students of the auxiliary school [Text] / L. V. Zankov. - M .: Publishing house "APN RSFSR", 1976. - 279 p.

8. Zankov, L. V. Some questions of personality development of mentally retarded schoolchildren at the first stages of education [Text] / L. V. Zankov. - M .: Publishing house "APN RSFSR". - 307 p.

9. Zankov, L. V. Questions of psychology of students of the auxiliary school [Text] / L. V. Zankov. - M .: Publishing house "APN 
CURRENT RESEARCH JOURNAL OF PEDAGOGICS 2(11): 115-121,

November 2021 DOI: https://doi.org/10.37547/pedagogics-crjp-02-11-21

ISSN 2767-3278

(C)2021 Master Journals

Crossref do: 81 Google

Accepted 25th November, 2021 \& Published 30 ${ }^{\text {th }}$ November, 2021

RSFSR", 1976. - 279 p.

10. Aytmetova S.Sh. Features of mental development of secondary school students. T .: "Teacher", 1984.

11. Vinogradova A.D. Workshop on the psychology of a mentally retarded child. M .: Enlightenment, 1985.

12. Vygotsky L.V. Development of higher mental functions. M .: Enlightenment, 1976.

13. Mamedov K.Q., Shoumarov G'.B. Psychology of mentally retarded children. T .: "Teacher", 1994.

14. Bespalko V.P. Pedagogy and progressive teaching technologies. M .: 1995.

15. Rubinstein S.Ya. Psychology of a mentally retarded student. M .: 1986.

16. Djuraeva, N. D. (2019). Study of issues of attitude to the place and role of women of Uzbekistan in society in the XX century. Academia Open, 1(1).

17. Djuraeva, N. D. (2020). THE PLACE AND ROLE OF WOMEN IN SOCIETY IN THE PRE-ISLAMIC PERIOD. INTERNATIONAL SCIENTIFIC AND TECHNICAL JOURNAL "INNOVATION TECHNICAL AND TECHNOLOGY”, 1(2), 62-68.

18. Dalibaevna, N. D. (2021). The Social Activity of Women Is One of the Important Factors in the Development of the Country. Eurasian Journal of Social Sciences, Philosophy and Culture.

19. Sayfullaev, N. (2021). The Name of Our Country Will Be Praised By The Followers Of Kamoliddin Bekhzod. The American Journal of Social Science and Education Innovations, 3(04), 402-408.

20. Karimov, N. R. (2020). A True Successor of Great Central Asian Scholars. Journal
«Bulletin Social-Economic
Humanitarian Research,(7),

and 